\title{
ERRATUM
}

\section{Trayless cafeterias lead diners to take less salad and relatively more dessert - ERRATUM}

\author{
Brian Wansink and David R Just
}

First published online 31 March 2015

doi:10.1017/S1368980013003066. Published by Cambridge University Press 18 November 2013.

This paper was published with an error in the legend of Figure 1. The legend showed "with tray service" represented by the hollow bar and "without tray service" as a solid bar. This should have been the reverse. The correct legend reads as follows:

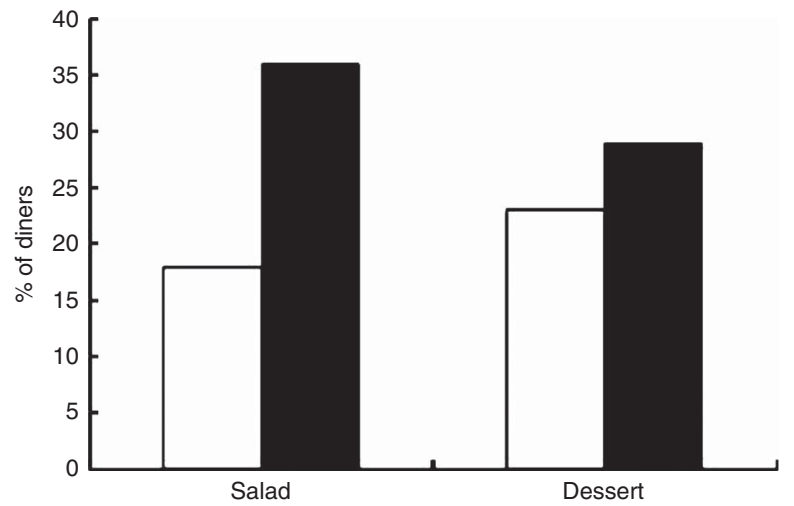

Fig. 1 When cafeterias go trayless, a smaller percentage of diners take salad; field study conducted among undergraduate students ( $n$ 417; average age 19.1 years) on two evenings with identical menus, one with tray service ( $\square$ ) and one without ( $\square$ ), in a university cafeteria, north-eastern USA

\section{Reference}

Wansink B \& Just DR. Trayless cafeterias lead diners to take less salad and relatively more dessert. Public Health Nutrition, published online by Cambridge University Press 18 November 2014, doi:10.1017/\$1368980013003066. 